\title{
Developments in financing and reforming the health care system in Albania, the road ahead
}

\author{
Alba Robert Dumi ${ }^{1,2}$, Zamira Sinaj ${ }^{3}$ \\ ${ }^{1}$ Institute for European Studies, University of Tirana, Albania \\ ${ }^{2}$ Dean of Graduated School, “Ismail Qemali”Vlore University, Vlore, Albania \\ ${ }^{3}$ Management Department, “Ismail Qemali” Vlore University, Vlore, Albania \\ Email address: \\ alba.besi12@gmail.com (A. R. Dumi) zsinaj@yahoo.it (Z. Sinaj)
}

\section{To cite this article:}

Alba Robert Dumi, Zamira Sinaj. Developments in Financing and Reforming the Health Care System in Albania, the Road Ahead. Science Journal of Public Health. Special Issue: Health Behavior and Public Health. Vol. 3, No. 1-1, 2015, pp. 14-19. doi: 10.11648/j.sjph.s.2015030101.13

\begin{abstract}
The Albanian Health sector is in the continuing transformation in the function of the realization of the proper standards. To realize the reform in this sector and to help the decision makers in their decision is necessary to have the right information on the source of the financing of health sector, on the destination of the expenditure in this sector and their control. "The establishment of the National Health Service is an integral part of the new Albanian Government program and it is also the fairest intervention intended to upgrade the system of service financing at the levels required by providers and recipients of health services. In this paper research we are try to present the current situation concerning our insurance scheme, developments in financing the primary health care and hospital sectors, our future projects to improve the way of financing hospital services, etc. were displayed in this presentation. We are in focus of Albanian reforms, improvement of the services and we are studying the health costs for health services.Our learning and evaluation team reviewed every incoming evaluation to ensure that it met the quality standards in our policy. When evaluations failed to meet the standard, the three most common concerns, wich are analyze in this paper: (1) evaluation teams received too many questions-especially questions that are too general and ill-defined-relative to the resources available for the evaluation, (2) the data collection and analysis methods were not appropriate to answer the evaluation questions, or (3) evaluation reports.
\end{abstract}

Keywords: HIV Aids, Health Sector, National Service, Progress, Health Service, Performance

\section{Introduction}

The term health insurance is commonly used in our country to describe any program that helps pay for medical expenses, whether through privately purchased insurance, social insurance or a social welfare program funded by the government. Synonyms for this usage include "health coverage," "health care coverage" and "health benefits." In this paper research we want to present the new low reforming in health care system in Albania.Like any robust reform process, we face significant challenges across a spectrum of efforts. (Gottler A. Focus 2014)

This article presents a summary of the current status, of health Albanian system. The developing health care system of undergraduate, postgraduate and continuous medical education in Albania and suggests opportunities for development and partnerships that would help the country's medical education reform.

\subsection{Albania and European Experience}

Albania's population is younger than that of other European countries. A third of its 3.1 million inhabitants is under the age of 15 , and $40 \%$ is younger than 18 . The population grew by $1.2 \%$ per year in the period 1980-1999, with a fertility rate in 1999 of 2.4 children per woman of childbearing age (1-2). The country experienced even higher population growth in earlier decades, encouraged by the pronatalist policy of the Communist regime. (Nuri B 2002)

Designing country strategies, in Albania was more time and labor intensive than originally anticipated, particularly because a large number of partners were engaged in the process to determine tough trade-offs. (Golennt R JERM 2012) In the year ahead, we will continue to prioritize the 
development of country strategies and enable better coordination with our partners to reconcile competing priorities and focus on areas where we each have a comparative advantage. (Hana E, ISKSH 2012)

Our effort to focus our assistance programs has been successful for the past two years either because we successfully exited from sustainable projects or because our programming was too minimal to have a true impact. As we look ahead, we must continue to make tough choices and use each country's strategy as the backbone for decision-making to ensure the greatest development impact.The health sector is defined as the priority sector in the Albanian Strategy for the social and economic development.

\subsubsection{PHC Provider Payment System and Albanian Health Care Amount}

From 1995 through 2007, HII funded only GP salaries. It was clear during this transition period that HCs had little or no management or operational autonomy. $\mathrm{MOH}$ and the HCs themselves were unable to monitor important elements of their medical activities, and no one was directly responsible for the success or failure in providing services to the population. (National Health Accounts (NHA), Albania, July 27, 2010)

The HCs had no indicators for measuring and evaluating the performance of providers, and there were few financial and professional incentives to improve the quality of their services. In 2007, the GOA initiated a comprehensive reform of the health system. This led to a change in the method of funding providers, and began the transition of HII to a single-payer. This was followed by steps to consolidate the PHC budgets in HII, and to allocate it by region, and then to allocate it by Health Center. (Dumi A, MSCER 2009)

The Director of the HC (as well as a Board) would be responsible for managing the funds in the bank accounts for each HC. A contract process was designed between HII and each $\mathrm{HC}$ to specify the package of services to be provided in the $\mathrm{HC}$ in order to receive payments from HII. (National Health Accounts (NHA), Albania, July 27, 2010)

\subsection{Health Care Reform and Management of the Civil Servant in Albania}

The Economics of Public Health Care Reform in Advanced and Emerging EconomiesPublic administration reform is another key priority of the Opinion. The adoption in May of the Civil Service Law, one of the measures required for obtaining candidate status, was a major step towards de-politicising public administration. The law, entering into force in October, is essential for building a professional, effective and merit-based public administration. It aims to create a consistent legal framework comprising state administration, independent institutions and local government units. It provides a clear classification of civil servants formally establishes a top-level management civil servants corps and provides the basis for a transparent recruitment and promotion system. (USAID, Albanian Reform 2013, pp 13)

\section{Health Management Administration}

HII was created in 1994 based on Law No. 7870.8 HII was organized as an autonomous legal entity and autonomous administrator of the health care insurance fund HII's main governance structure is the Administrative Council (AC). (Commission working document, Albania Doc Brusel 2014).The Administrative Council includes 11 representatives, one each from of $\mathrm{MOH}$, Ministry of Labor, Social Affairs and Equal Opportunities, and MOF, the General Director (GD) of HII or his/her representative, the Director of the Social Insurance Institute or his representative, a representative of the workers' syndicate, a representative of the health care providers as defined by the Order of the Medical Doctor, a representative of the self-employed individuals and a representative of the consumers' association who represent the beneficiaries of the Fund The law abrogates existing legislation without providing the necessary transitory provisions until its implementing legislation enters into force; the government approved in September 2013 technical amendments to avoid this legal vacuum. (MOH Report 20013)Timely adoption of the secondary legislation compliant with the principles of the law and proper implementation is essential. The Law on General Administrative Procedures is still pending.

\subsection{Social Environment and Social Effects}

The attitudes community residents have toward development and the specific actions being proposed as well as their perceptions of community and personal well-being are important determinants of the social effects of a proposed action. Such attitudes are a reflection of the quality of life residents seek to enjoy and preserve, whether it is limiting growth in order to maintain the rural image of a small community; expanding the boundaries of the village; or providing a variety of housing choices to new, diverse residents and businesses. Changes in a community's social well-being can be determined by asking the individuals and representatives of groups or neighborhoods in the area to make explicit their perceptions and attitudes about the anticipated changes in the social environment.

\subsection{Curent Reforms in Health Care System}

Corruption in the health sector is not an isolated phenomenon, but occurs in other public structures causing a general service failure. Addressing irregularities such as informal payments, improving procurement and distribution of drugs and supplies, increasing staff salaries/wages and so on requires an integrated anti-corruption strategy and strong political backing. Any health reform to be undertaken has to take into consideration the existing informal payments, as gifts or as 
unofficial payments, made by own willingness or not. (Dumi A DRSKSH 2007)

Recently the rules for formal payments from the uninsured persons are being enforced, this is supposed to decrease the informal payments, but at the same time this carries the risk of excluding the poorest from health care service. Reforms should provide protection to the most vulnerable social groups, as poor, elderly, Roma and Egyptian minority, etc. Some of the current reforms undertaken or envisaged by the government are: the patient referral system; introduction of official fees; calculation of service costs; and digitalization and 'informatization' of the health care system. (ISKSH Albania reforms 2013)

\section{Literature Review and Hypotheses}

The share of Americans with health insurance has been steadily declining since at least 2000. As of 2010 just fewer than $84 \%$ of Americans had some form of health insurance, which meant that more than 49 million people went without coverage for at least part of the year. Declining rates of coverage and underinsurance are largely attributable to rising insurance costs and high unemployment. As the pool of people with private health insurance has shrunk, Americans are increasingly reliant on public insurance. Public programs now cover $31 \%$ of the population and are responsible for $44 \%$ of health care spending. Public insurance programs tend to cover more vulnerable people with greater health care needs. (USA Health indicators, Logann, Internet link, 2012)

Health care models such as Wagner's Chronic Care Model (CCM) and Patient-Centered Medical Home (PCMH) promote a safety culture for patients. (Wagner Health Model 2013) CCM promotes health care delivery systems designed to support community-based resources, self-management of care, and information support systems. Information support systems provide the basis for much of the continuity in patient records and clinician communication. In a more technical sense, the term is used to describe any form of insurance that provides protection against the costs of medical services. (ISKSH Vlore 2007)This usage includes private insurance and social insurance programs such as Medicare, which pools resources and spreads the financial risk associated with major medical expenses across the entire population to protect everyone, as well as social welfare programs such as Medicaid and the State Children's Health Insurance Program, which provide assistance to people who cannot afford health coverage. (Meddings F \&Gottler A. Focus 2014). In Albania health care system, we are trying to implementation these good experiences.

\subsection{Some Data in Albanian Conditions}

The contribution rate for employees' person is $3.4 \%$ of month salary, whereof $1.7 \%$ paid by employer and $1.7 \%$ by employees. The self-employers contribution rate at urban areas is $7 \%$ of the minimal salary, meanwhile the self employers at the rural areas pay $3 \%$ of the minimal salary, at hilly and mountain areas, and at the field areas is $5 \%$. The voluntarily insurance is another opportunity to be insured. (Bishop, E. B. 1996)

The contribution rate is $3.4 \%$ of minimal month salary. Budget for the year 2011 is estimated to amount to 27.4 billion, or a $7 \%$ increase compared to 2010. This growth will make possible a salary increase of $4-5 \%$ on average for other health sector employees. The amount to be allocated for the drugs reimbursement will be also increased and it will amount to Lek 6.7 billion (Source: ISKSH, year 2010)

Table 1. Data analyze on 2010 year indicators of the health services utilization through health insurance scheme. (Source: ISKSH, year 2010)

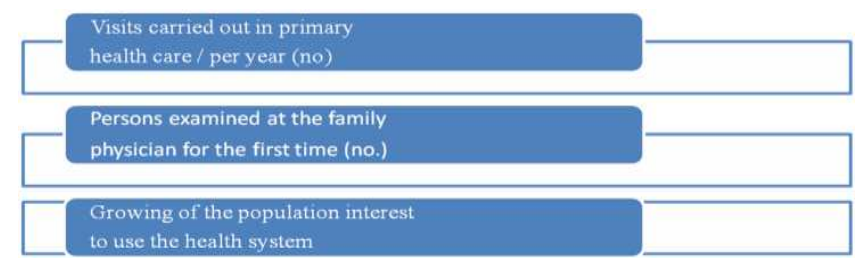

The new residents and their associated activities will require a variety of services pro-vided by the areas public and private institutions. A social impact assessment must determine the quantity and variety of anticipated needs. The goods and services most commonly included in a social evaluation are open space and parks; cultural and recreation facilities; education; health care; special care for the elderly, the disabled, the indigent and preschool-age children; police and fire protection; and a variety of administrative support functions. (Gotemm S, Jesr Usa, 2014)

The optimum amount of resources that would be required for the satisfaction of needs is based on either planning standards, which are guidelines established by professional organizations and government agencies, or service levels, which are observed national (or regional) average amounts of resources expended per capita or some unit of size.

H1: Albanian new health insurance law reforming in Albania, as a new vision of the health care system under EU standarts.

Health care costs have been growing rapidly in the past several decades. Since 1970, total real per capita health spending has increased fourfold, while spending as a share of GDP has increased from 6 percent to 12 percent in advanced economies. In emerging economies, total health spending has increased from below 3 percent of GDP to 5 percent. These increases have put great fiscal pressure on governments and financial pressure on households and businesses.

H2: A local health finance specialist was deployed prior to the arrival of two international consultants to perform the initial identification, collection, and review of documents relevant to HII's evolving history and mission, organizational structure, processes, and relationship with other health sector institutions.

The Health Insurance Institute (HII) has made significant progress over the last 15 years to movetoward a 
single-payer model for the implementation of compulsory health insurance coverage in Albania. This progress has been made in coordination with a national strategy for health reform bythe Government of Albania (GOA), the Ministry of Health (MOH), and other GOA and healthsector institutions. (ISKSH journal 2013)

H3: The services have started to be fragmented and a higher priority is given to the quantity than to the quality. That the health insurance scheme currently includes all vulnerable categories, categories which are covered by the Albanian state

New programs, from mentoring to training to individual consulting support, can help support our next generation of development leaders, no matter where they are from.The National Health Accounts 2003 estimate that Albania spent 43.8 billion Lek (USD 360 million) overall on the health sector and per capita expenditures of 13,983 Lek (USD 114.7).

\subsection{Public Services and Social Impact of Variety of Life}

The total expenditure on health is 5.9 percent of the GDP and is significantly higher than previous estimates that had placed health care expenditures at $2.9 \%$ of GDP. This level of expenditure is more in line with middle income countries and is lower than the average for European neighbor's countries. These partnerships do not mean that we write blank checks to foreign governments. Assessments are used to identify specific institutions that will be good partners.

\subsection{Macroeconomic Stability and Influences in Health Care System}

The imperfections in the health care market imply that governments must play an important role. However, there is no single model that delivers the best results across all countries. The pervasiveness of market failures and a desire to ensure that access to basic health care reflects need and not ability to pay have motivated extensive government involvement in this sector in advanced and emerging economies (Musgrove, 1996). The nature of government intervention (e.g., mandates, regulations, provision, and financing) has varied substantially across countries and over time, as has the level of public health spending. Source: (The economics of public health care reform in advanced and emerging economies, David C\& Sanjeev G. - Washington, D.C)

\section{Methodology}

\subsection{Research Goal}

In this survey we aim to identify the mediating affect of Albanian health care reforms, under EU consideration we inspirate to go ahead. The review was conducted in AprilDecember 2011, 2012, January -December 2013. We are formed 50 questionaries in health care institutions and 30 questionaries with ill people. The methodology used for the review consisted of:
- Collection and review of background documents prior to field work;

- Meetings to discuss objectives and processes with the EEHR team at the project office;

- Interviews with USAID and other counterparts;

- Interviews and data collection with key stakeholders at HII, MOH, and other relevant health

- sector institutions; DRSKSH (Directory of health care services) in Vlora, Tirana, Shkodra

- Interviews and data collection with key stakeholders at Vlora University, Albania and other relevant projects of master thesis in Vlora University

- Institutions and Municipalities of Vlora, DRSKSH (Directory of health care services) in Vlora, Tirana, Shkodra.

- Site visits to regional facilities (Vlora, Tirana, Shkodra) and a private hospital in order to observe conditions and discuss various issues, relationships, roles, and responsibilities

- Analysis of findings and presentation of recommendations.

Table 2. Coherent links among - infrastructure and economic development, Musgrove theory 1996, Indicators of sensitively and performance \left. criteria[Indicators and choices] [Mr to ${t^{\wedge}}_{g}^{D B} \mathrm{Mx}\right]$

\begin{tabular}{cccccc}
\hline & $\begin{array}{c}\text { Indicator } \\
\text { A }\end{array}$ & $\begin{array}{c}\text { Indicator } \\
\text { B }\end{array}$ & $\begin{array}{c}\text { Indicator } \\
\text { C }\end{array}$ & $\begin{array}{c}\text { Indicator } \\
\text { D }\end{array}$ & $\begin{array}{c}\text { Criteria } \\
\text { X }\end{array}$ \\
\hline $\begin{array}{c}\text { First } \\
\text { choice }\end{array}$ & 42 & 18 & 57 & 59 & 66 \\
$\begin{array}{c}\text { Second } \\
\text { choice }\end{array}$ & 42 & 7 & 5 & 63 & 41 \\
\hline
\end{tabular}

$\mathrm{M}_{\mathrm{R}=} \frac{n 1(n 1+n 2+1)}{2}=\frac{4(4+5+1)}{2}=20$ cases of health treatment $\mathrm{Mr}+\mathrm{Ms}=$ Ifs $20+\stackrel{2}{57 / 4})=$ Ifs

The synthetic estimator for function code $f$ of state $g$ is:

Equation, $\mathrm{Mr}+\mathrm{Ms}=$ Ifs $20+18+57+59+66(5 \mathrm{CNRI} / 5$ Indicators of criteria A-X) = Ifs

Table 3. The indicators of treatments and HCF Performance, Glueck theory 1984

\begin{tabular}{|c|c|}
\hline & ${ }^{x} g f$ \\
\hline & $\hat{Y^{S}{ }_{g f}}=\quad \sum_{f}^{\infty} g f \quad{\hat{t_{g}}}^{D B}$ \\
\hline where & $\begin{array}{ll}\text { These indicator is auxiliary information } & \\
\text { which is Mrs+ Mss (indic of perf)* } & \\
\text { Miq( indic of quality)* Mdt(indicator of } & \begin{array}{l}\text { from patient and } \\
\text { dreatment of ill }\end{array} \\
\begin{array}{l}\text { disease treatment)/ number of emergent } \\
\text { case month }\end{array} & \text { portion of } \\
\begin{array}{l}\text { Obtained (first choice and second } \\
\text { choice) are indicated }\end{array} & \end{array}$ \\
\hline Census & $\begin{array}{l}\text { of Government and the state total, } \hat{t}_{g}^{D B} \text { is obtained by the } \\
\text { Decision-based from The indicators of health care are: } \\
\text { In }\{0-25\} \text { to }\{26-123\} \\
\text { It depends by the choice. The level of the mistake is in the } \\
\text { rank below: }\end{array}$ \\
\hline
\end{tabular}

Equation, $\mathrm{Mr}+\mathrm{Ms}=$ Ifs $20+(57 / 4)=$ Ifs

In this study the criteria of indicator of sceerining is very high.

Given the increasing incidence of breast cancer disease and considering the important social policy struggle against 
this disease, we have set an important indicator for screening $80 \%$ of women at an age of risk (over 35 years) by the family physicians. With this result we treat the hypothese $\mathrm{H} 1$ and $\mathrm{H} 2$,

Indicator of HCF performance, this indicator, which is now part of the indicators of quality service, has been added so that the disease is caught in time, the increasing success of the treatment of these cases and decrease of mortality.also, another indicator of quality that has been added to the contract, has to do with a better examination of patients suffering from diabetes, taking account of the fact that this is a disease in expansion (we treat about 510 new cases per month) and with major consequences for the population.

Table 4. The indicators of treatments, values of research, $H C F$ Performance of recover in hospital, Linear math theory Linkersonn 2003

\begin{tabular}{llllllllll}
\hline values & $\underline{\mathbf{2 1}}$ & $\underline{\mathbf{1 4}}$ & $\underline{\mathbf{5 5}}$ & $\underline{\mathbf{2 6}}$ & $\underline{\mathbf{2 7}}$ & $\mathbf{4 7}$ & $\mathbf{1 7}$ & $\mathbf{2 8}$ & $\mathbf{2 9}$ \\
\hline $\begin{array}{l}\text { Ranks } \\
\begin{array}{l}\text { Performance } \\
\text { of recover }\end{array}\end{array}$ & 1 & 2 & 3 & 4 & 5 & 6 & 7 & 8 & 9 \\
\hline
\end{tabular}

Mrs+ Mss (Indic of perf)* Miq (Indic of quality)* MDT (Indicator of disease treatment)/ number of emergent casrs for month

\section{Recommendations}

The following recommendations emerged from this institutional review of HII. The consultant team encourages Albanian stakeholders to review and discuss the recommendations in light of the sector's health reform strategy, future plans, and available resources. Recommendations may be discussed within HII, among other health sector stakeholders including the $\mathrm{MOH}$ and NCQSA, and even by the Prime Minister's task force or at other Government levels as appropriate. Health care insurance institute has approved the new contracts with health services providers of all levels for 2013, putting the emphasis on funding at best the health centers based on the quality provided to patients, extraction of hospital services' costs and stricter controls for reimbursable drugs from the contracted pharmacies.

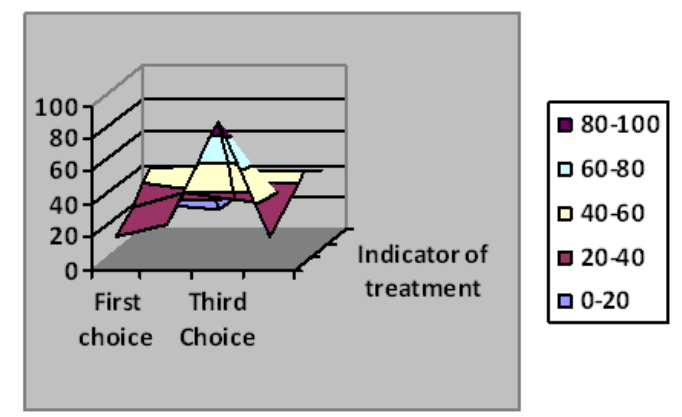

Graph 1. The indicators of treatments, values of research, HCF Performance of recover in hospital, Linear math theory Linkersonn 2003[Indicators of treatments and choices of performance levels, HLI ages [0-20]to[80-100]

\section{Conclusions}

All citizens of the Republic of Albania benefit from health insurance schemes, whether contributory or vulnerable categories, since the state contributes for the later. The contract emphasis the increase of the healthcare quality provided to the patients, through building capacities of health care personnel. This will be achieved by the physicians' active participation in the system of Continuous Medical Education, as one of the priorities of HII funding policies. Another way of improving the health services quality is the financial motivation of health personnel based on everyone's performance and contribution.

The public hospital sector remains underdeveloped whereas the private sector is growing without proper regulation. The Ministry of Health signed a contract in January 2014 for the establishment of a National Electronic Health Record (NEHR) system but the necessary financial resources still need to be secured. The draft of health strategy has not yet been adopted. For one reason or another, the services have started to be fragmented and a higher priority is given to the quantity of services, than to the quality of health concept in general.The new vision of Health care strategy in Albania is motivated extensive government involvement in this sector in advanced projects and future plans. With regard to communicable diseases, a new draft Law on the control of infectious diseases remains to be adopted and national guidelines on antimicrobial resistance are being drafted. At the national level, reported immunisation coverage for 2013-2015 was over $98 \%$.

\section{References}

[1] Albanian Finance incomes 2009, pg 10, 45, Albania and reforming economy, www.economy Albania, com

[2] Albania Government journal, pg 14, 27, 39 years 2009, Albania Economy statistic facts Albanian government for educational priorities, report $2010 \mathrm{pg} 12,25,41,58,74$

[3] Alba DUMI, Roma Italy, "AIJS Journal" The role of university in reformin of public sector" 2012, pp 135

[4] Alba DUMI "Albania health system under European Health indicators of development strategy", May, 2010, JERM, Jounal publish in USA, pp 1567

[5] Bishop, E. B. "ROCE as s Tool for Planning and Contol", Long Range Planning, 2, 4, 1969, 80-7.Bradler\& Sediss The raport Company: Kingston, Ontario

[6] Egamberdi, Nilufar; Center for Economic and Social European Communities, L175, pages 40-48 “

[7] Glueck, W.F. and Jauch, L. R. Business Policy and Strategic Management, $4^{\text {th }}$, edn, McGraw-Hill, New york, 1984

[8] An Overview of Public Administration in Albania pg 6 year 2008, THANASI Durata (Internet link)Albanian publisher by Albania international bank 2010, report APA, net

[9] Albania Demographic and Health Survey 2008 - 09. Tirana, Albania: Institute of Statistics, Institute of Public Health and ICF Macro. 
[10] Bodie Zvi (Nobelist), "Educational reforming strategy" Merton Robert, Finance, (2002), foreword from Paul Samuelson, Nobelist.
[11] Nuri, B. In: Tragakes, E., ed. Heath care systems in transition: Albania. Copenhagen, European Observatory on Health Care Systems, 2002: 4(6) 